\title{
4D flow MRI of the aorta becomes practical: performance and observer variability for a new semi-automated workflow for 3D visualization and quantification of aortic hemodynamics
}

\author{
Susanne Schnell ${ }^{1 *}$, Pegah Entezari ${ }^{1}$, Riti J Mahadevia ${ }^{1}$, Daniel Rinewalt ${ }^{2}$, Jacob Fluckiger ${ }^{1}$, Jeremy Collins ${ }^{1}$,
} James Carr ${ }^{1}$, Bernd A Jung ${ }^{3}$, Michael Markl ${ }^{1,4}$

From 16th Annual SCMR Scientific Sessions

San Francisco, CA, USA. 31 January - 3 February 2013

\section{Background}

To systematically investigate the performance and interobserver variability of a new standardized workflow for the analysis of aortic hemodynamics based on 4D-flow MRI in a study with 30 subjects. The semi-automated workflow was developed to ensure faster and standardized data analysis including systematic placement of analysis planes, 3D-flow visualization, and quantification of standard clinical flow parameters.

\section{Methods}

ECG and respiration-synchronized flow-sensitive 4D MRI data (spatio-temporal resolution $=2.1-2.9 \times 2.1$ $2.5 \times 2.5-3.2 \mathrm{~mm} 3 / 37.6-40 \mathrm{~ms})$ were acquired in 10 healthy volunteers, 10 patients with dilation of the ascending aorta and 10 patients with bicuspid valves (BAV). After correction for noise, eddy-currents and aliasing (Bock et al, ISMRM 2007), the data were loaded into a 3D visualization software (Ensight, CEI, USA). A set of macros was developed (in python) to minimize user interaction, permit a reproducible definition of analysis planes, and reduce time needed for comprehensive 4D-flow analysis. This included 1) automated calculation of 3D PC-MRA; 2) creation of 9 standardized analysis planes to be positioned manually along the aorta; 3 ) quantification of net, forward and reverse flow, regurgi- tation and peak systolic velocity; 4) 3D-flow visualization by time-resolved pathlines; 5) saving and export as images and movies (for presentation purposes and transfer to the hospitals PACS system). Steps 3-5 were fully automated. For evaluation, the data was analyzed by two independent observers, and agreement was tested in 3 analysis planes (mid-ascending aorta, mid-arch and proximal descending aorta).

\section{Results}

In all 30 subjects the analysis was successfully completed and provided comprehensive information on aortic hemodynamics including planar flow quantification, and 3Dflow visualization with a 3D viewer (Enlighten, CEI, USA) as well as in standardized views as standalone videos and images. As summarized in figure 1 and table 1, inter-observer agreement was excellent for peak velocity, reverse flow and regurgitation (mean differences $4.59,0.94$ and $3.36 \%$ of the average parameters). The net and forward flow demonstrated moderate agreement (mean differences 5.4 and 5.1\%). The mean analysis time for the complete analysis was $80 \mathrm{~min} \pm 28$. Note that the time was prolonged by the processing time needed generate the image and video files. For steps 1-4 only the analysis time was substantially reduced to $37.2 \mathrm{~min} \pm 12.5$. The average time for noise, eddy currents and aliasing correction was $13.4 \mathrm{~min} \pm 5.8$. 


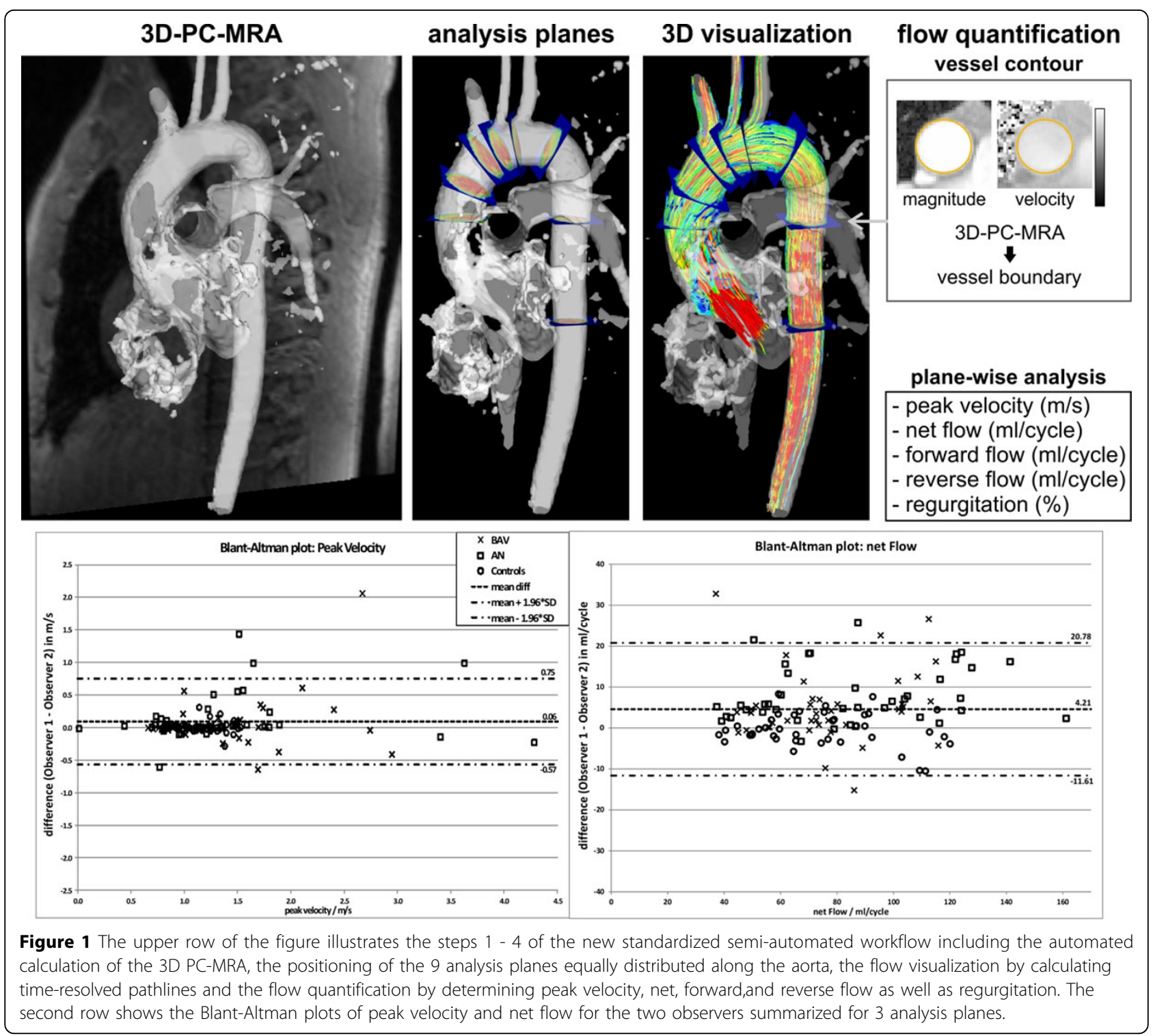

Table 1 Quantification results showing the mean values, mean difference between the two observers and its limits of agreement (LOA)

\begin{tabular}{|c|c|c|c|c|c|c|c|c|c|}
\hline & $\begin{array}{l}\text { Mean } \\
\text { Controls }\end{array}$ & $\begin{array}{l}\text { Mean } \\
\text { BAVs }\end{array}$ & $\begin{array}{c}\text { Mean } \\
\text { Aneurysms }\end{array}$ & $\begin{array}{l}\text { Mean } \\
\text { Total }\end{array}$ & $\begin{array}{l}\text { Mean Difference } \\
\text { Controls }\end{array}$ & $\begin{array}{c}\text { Mean } \\
\text { Difference } \\
\text { BAVs }\end{array}$ & $\begin{array}{l}\text { Mean Difference } \\
\text { Aneurysms }\end{array}$ & $\begin{array}{c}\text { Mean } \\
\text { Difference } \\
\text { Total }\end{array}$ & $\begin{array}{c}\text { LOA } \\
\left(+/-1.96^{*} \mathrm{SD}\right)\end{array}$ \\
\hline $\begin{array}{l}\text { Peak Velocity } \\
(\mathrm{m} / \mathrm{s})\end{array}$ & 1.16 & 1.31 & 1.22 & 1.32 & 0.02 & 0.10 & 0.16 & 0.09 & 0.66 \\
\hline $\begin{array}{c}\text { Net flow (ml/ } \\
\text { cycle) }\end{array}$ & 69.87 & 71.13 & 74.53 & 77.45 & -0.86 & 6.40 & 8.22 & 4.59 & 16.19 \\
\hline $\begin{array}{c}\text { Forward flow } \\
\text { (ml/cycle) }\end{array}$ & 70.53 & 73.73 & 77.16 & 79.40 & -1.21 & 6.13 & 8.31 & 4.41 & 16.00 \\
\hline $\begin{array}{l}\text { Reverse flow } \\
\text { (ml/cycle) }\end{array}$ & -0.85 & -2.48 & -2.72 & -2.00 & -0.01 & 0.03 & -0.26 & -0.11 & -3.11 \\
\hline $\begin{array}{c}\text { Regurgitation } \\
(\%)\end{array}$ & 1.23 & 3.54 & 3.93 & 2.71 & 0.05 & 0.32 & 0.15 & -0.04 & 3.56 \\
\hline
\end{tabular}




\section{Conclusions}

Standardized 4D-flow MRI data analysis based on a macro oriented workflow can be performed with good inter-observer agreement and provides comprehensive information of aortic hemodynamics. Improved computation speed and better algorithms for the calculation of $3 \mathrm{D}$ visualization are needed to further reduce analysis time to clinically acceptable times.

\section{Funding}

DFG (German Research Foundation) SCHN 1170/2-1.

\section{Author details}

${ }^{1}$ Dept. of Radiology, Northwestern University, Feinberg Medical School, Chicago, IL, USA. ${ }^{2}$ Cardiac Surgery, Rush University, Chicago, IL, USA.

${ }^{3}$ Radiology, Medical Physics, University Medical Center Freiburg, Freiburg, Germany. ${ }^{4}$ Biomedical Engineering, Northwestern University, Evanston, IL, USA.

Published: 30 January 2013

doi:10.1186/1532-429X-15-S1-M2

Cite this article as: Schnell et al:: 4D flow MRI of the aorta becomes practical: performance and observer variability for a new semiautomated workflow for 3D visualization and quantification of aortic hemodynamics. Journal of Cardiovascular Magnetic Resonance 201315 (Suppl 1):M2

Submit your next manuscript to BioMed Central and take full advantage of:

- Convenient online submission

- Thorough peer review

- No space constraints or color figure charges

- Immediate publication on acceptance

- Inclusion in PubMed, CAS, Scopus and Google Scholar

- Research which is freely available for redistribution

Submit your manuscript at www.biomedcentral.com/submit
C Biomed Central 